\title{
Math and Computer Science Education in a Liberal Arts University in Pakistan
}

\author{
Umair Azfar Khan \\ Department of Computer Science, \\ School of Science and Engineering, \\ Habib University, Pakistan
}

\author{
Yousuf Kerai \\ Department of Integrated Sciences and \\ Mathematics, \\ School of Science and Engineering, \\ Habib University, Pakistan
}

\begin{abstract}
Habib University prides itself in providing state of the art education to its students and aims to break many barriers that have been created in the past few decades. These barriers encourage the usage of techniques and methods that help in getting better grades at the expense of better learning. There are two main systems of higher secondary education in Pakistan which are the Higher Secondary Certificate (HSC) and the General Certificate of Education (GCE) A Level, as followed in England. With our experiences in education from different fields, we made it a priority to emphasize learning over reaching a correct solution. The methodology adopted by us emphasized that the students come up with their own solutions to problems and to encourage them to be wrong so that they can rectify their mistakes and arrive at the answer through learning where and why they went wrong. This results in creating a lot of eureka moments which these students rarely experience. In this paper we provide the efforts we made to improve learning and present results of these efforts. Our overall experience has been that we need to go through a process of unlearning old methodologies and employ new ones that emphasize on self-learning and experimentation. The results so far have been promising and we have seen our students' attitude change from indifference to one full of curiosity and enthusiasm.
\end{abstract}

\section{Introduction}

Habib University, ever since its inception in 2014, remains in the forefront of Liberal Arts and Sciences Education in Pakistan. It offers a transformative learning experience and aims to redefine higher education in the country by applying innovative techniques in pedagogy. Habib University also has a School of Science and Engineering which contains a
Department of Computer Science and Department of Integrated Sciences and Mathematics which are tasked with teaching subjects in Computer Science and Mathematics respectively. This gives an opportunity to students from Arts background to experience scientific subjects and even pick up a minor if they so desire.

Habib University's Talent Outreach, Promotion and Support Program (HU TOPS), provides an opportunity to talented students to be inducted purely on the basis of their score in the higher secondary education programs. Students who are enrolled in Pakistan's Board of Intermediate Education (BIE) or Federal Board (FB), or Aga Khan University Examination Board (AKUEB) have a chance to pursue a fully funded four-year undergraduate program at Habib University based on their academic talent and performance.

With our experiences, we have found that mostly the students that do clear the examinations and enter the university are lacking the underlying concepts when it comes to science, mathematics and even logical reasoning. Students have to go through a few weeks of an unlearning phase where habits that were acquired over the years are suppressed and special emphasis is placed on conceptual learning. This paper covers the methods and techniques that we adopted in order to help students overcome their deficiencies and gain sound understanding of concepts which has been missing throughout their higher secondary education.

\section{Status of education}

In Pakistan, like many other countries, when a student enters undergrad studies, s/he has about 12 years of education. During the undergrad studies the student completes 16 years of education and graduates as a Bachelors in his/her field. However, there is a very small number of students who actually 
reach the level of Higher Secondary Education. Not having enough schools, poor basic education and poverty are a few main reasons that cause the students to not pursue any further education. At the same time, the female students are not encouraged to study due to archaic social and traditional reasons.

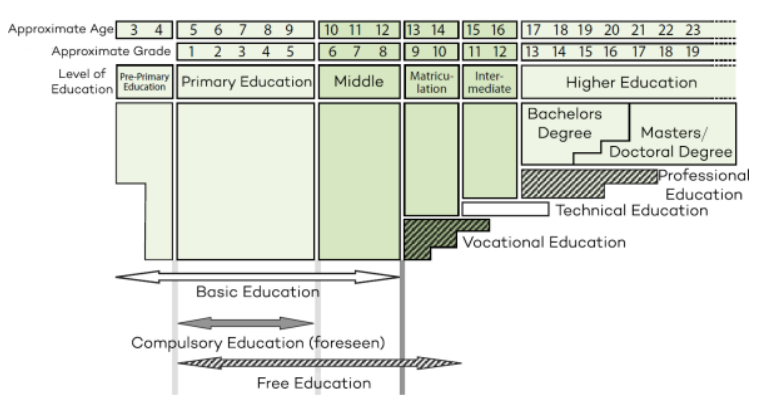

\section{Figure 1. Education Structure: Approximate Starting Age and Duration [1]}

Only $1.98 \%$ [2] of all the educational institutes in Pakistan cater for the needs of students in Higher Secondary Level. Out of these students not everyone ends up in universities. Generally, all universities require the students to score at least $60 \%$ in their higher secondary education to be eligible for the university selection examinations.

Private sector universities are quite expensive and with a dearth of public sector universities, only a few students manage to get enrolled in a university to pursue their undergraduate studies. There are, however, many scholarships available for excelling students which gives them the opportunity to pursue an undergraduate degree. Even with this selection procedure, not all students are ready or prepared to start their undergraduate studies.

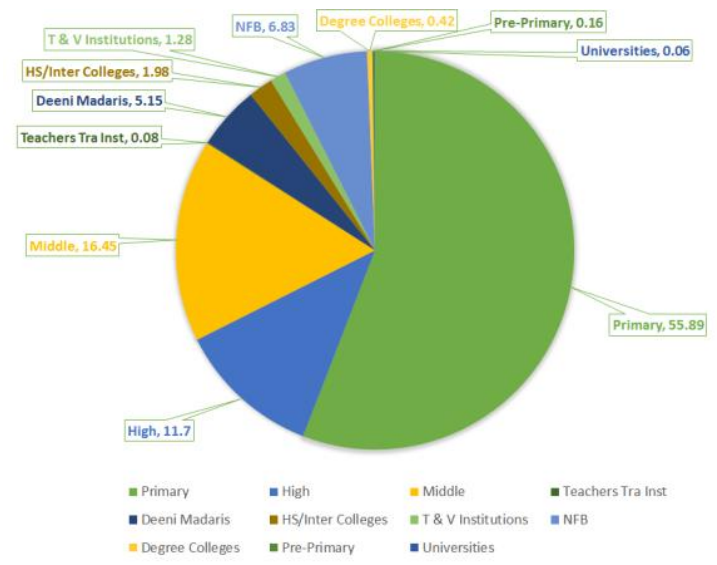

Figure 2. Distribution of Institutions by Level of Education, Pakistan, 2013-14 [2]

The level of the students changes drastically depending on their economic class or the region from which they belong. Bringing them all to the same level and making sure that everyone learns at the same pace is an extremely difficult task.

\section{Challenges in learning}

Pakistan has a plethora of public and private sector schools that provide the necessary education to students for the first 12 years of their school life. Even though the education acquired in these schools should be enough to prepare the students for university selection examinations, mostly the parents find it necessary to let their children go through a series of private tuitions. The aim of these tuitions is to provide the students with the necessary skills to approach the examination questions rather than understanding the underlying concepts. This is very much analogous to rote learning and kills the inherent creativity and critical-thinking skills of the students.

We have also seen that the aim of the students is to arrive at the correct solution through methods learned and formulae memorized. The reasons behind why a methodology is used or why a formula is applied are lost to them. In their minds they assume that following a series of steps mechanically is the best exhibition of their capabilities. We even had instances where students rote learnt entire computer programs to pass an exam. Such an instance was extremely alarming for us and we had to change our teaching methodology to help the students understand the concepts behind programming.

At Habib University, the emphasis is always to enable students to have a basic understanding on top of which they can build and extend their knowledge by going through books and online content. Students however have a totally different take on the subject material; they will only read their course books if chapters have been marked by the instructor and will only review handouts given in class. Mostly students show no initiative in learning on their own or finding content online. We have realized that properly using the search engines and arriving at the desired information is a skill which most students lack. Students shy away from reading and most of all want someone else to help them solve assignment problems for them. They do this with the intention to learn how a particular problem was solved rather than using their own capacity to come up with a solution. A few students have also said that they can only arrive at a solution if someone sits with them and acts as an observer, stepping in when they get stuck. This indicated to us that we need to have more emphasis towards a flipped classroom environment and at the same time help the students become more independent. 


\section{Enhancing learning}

The problems mentioned above puts the instructor in a very precarious position. On one hand, the course content needs to be covered during the semester but then there is no point in pushing forward with the course content if most of the class does not have the necessary understanding of the foundations. The decision was taken to concentrate on helping the students build their foundations for math and logical reasoning before moving forward in courses that had to do with Calculus and Computer Science.

\subsection{Learning in Computer Science}

Most of the students who come to Habib University have no idea about computer programming and logical reasoning. In the beginning, a programming console for the students can become extremely overwhelming and it can result in having them reject programming entirely. Many students especially from the humanities department, do not see the need to learn programming and thus show no interest in it. It becomes difficult to teach such students as they have already built up some resistance towards any sort of programming. We have introduced Python as the starting language as it is easy to learn and does not appear to be daunting to the students with its syntax. It gets more work done with a few lines of code and gives a lot of power to the programmer. We had hoped that this will make programming easier to get into but there were many issues that cropped up as we started teaching. We will go through these issues one by one to highlight the problems at hand and to explain the methodology we used to solve them.

4.1.1. Logical reasoning. Students fail to understand the usage of basic mathematical concepts in formulating logic. Helping them understand basic conditional statement and loops can take some time. The best way we found to explain this was to take them through the code line by line and asking them, repeatedly, what each line of code meant. This helps them formulate the picture in their heads and helps them understand the code and its flow. Flow charts have been helpful as well as it shows them the flow of the program graphically and they are better able to visualize it.

4.1.2. Debugging. Mostly students write the entire program and then start to debug it. They do not test the program while they code to check whether their code is actually working. We have seen a large number of students who are stuck in their own code because they cannot make sense of why a certain error is occurring. In their minds, they have created the right code therefore, the error is a complete mystery to them. We had to teach them to check their program repeatedly and most importantly break a big problem into smaller chunks; solve the chunk and then move forward.

Initially, students do debugging manually and soon move to print statements. We have also seen that they find the print statements to be extremely useful for debugging and it became hard to teach them how to use a debugging tool offered by the Integrated Development Environment (IDE) for any programming language. We found it odd that even though we showed them clear advantages of using a debugging tool, they were still reluctant in using it. Many a times we had to stop helping them in fixing their code and asked them to use the said tool to find the fault in their code themselves. This again shows the reluctance of students to adapt new techniques when the old one seems to get the job done.

4.1.3. Self-learning. We found the students to be most reluctant in learning by themselves. This included reading books, tutorials or doing exercises. The concept of going through the reading material, understanding it and following proper instructions is an extremely difficult task for them. We have to keep in mind that most of the students are so used to getting work done for them that they were dependent on the instructors for the steps towards a solution.

Students always look for handouts and presentation slides which can give them an overall summary of the topics in question. Since many of the compiler errors are not given in the books, the students have a hard time understanding the errors and searching solutions online using search engines like Google. We normally need to go through a few tutorials teaching them how to conduct a Google search and to find appropriate information in books and on websites. We have to clarify, repeatedly, that a university is not a tuition center and should not be considered as such. They need to develop problem solving skills and gain the habit of searching appropriate information on their own.

4.1.4. Communication gap. Through our experiences, we realized that there is a certain amount of communication gap between teachers and students. Students find it hard to approach teachers with their questions and in doing so do not learn the important concepts in time. Their inability to communicate with the teacher leaves them with the option of asking their peers for help. Habib University has made a special coaching centre known as 'Ehsas Centre' which employs student tutors to help struggling students. The student tutors are selected through interviews that gauge whether they can provide the necessary help to the struggling students. Some research assistants, and even the course instructors, spend some hours in the Ehsas 
Centre to provide help to students. Since the students are normally engaged on individual basis, they do not feel the pressure of being singled out during the class. This has been slightly beneficial for the students but we still believe that there should be a better way to approach this problem.

Sometimes the students are given some tasks to be done in class while the instructor goes around checking their progress. This way the instructor gets to see the students' progress in real-time and gets a good idea about the nature of the problems faced by the students. As a result, the instructor gets to engage the students, and this helps in reducing the reluctance of the student in approaching the teacher with their problems.

4.1.5. Project-based learning. We shifted from the normal methodology of teaching a course through periodic evaluations in the form of quizzes, midterms and a final to one that was totally dependent on practical application of learned concepts. This methodology was applied to the Object-Oriented Programming course where the students were given an assignment on a weekly basis and they were supposed to provide a solution by next week. A total of 8 assignments were initially designed but later this number was reduced to 6 and the submission was changed to be biweekly. After every assignment, viva was conducted to check whether the students actually understood what they did in the assignment and to check for plagiarism. We should mention that the students who took this course belonged to either Computer Science or Electrical Engineering Department.

This changed the conduct of the students for the better. There generally came to be three types of students: those who submitted their own work, those who chose to submit incomplete work rather than copy it and those who submitted nothing at all for fear of getting caught for plagiarism. As a result, some students dropped out of the course earlier and only the students who were serious stuck around to take it to completion. This created a sense of responsibility in the students as they started to own up to their work. The dropout rate was around $20 \%$ as 15 out of a total of 74 students dropped out. These students then took the course during the summers and cleared with ease as they already knew the demands of the course.

Another positive change that we saw in the students was their eagerness to show their work once the project was completed. An open house was conducted at the end of the semester that was only limited to Habib University students. For their OOP course the students were tasked with creating games as their semester projects. Students either came up with creative ideas or implemented their own implementation of old games. These were displayed in the open house and students from all over Habib
University participated in testing them out. The results were overwhelmingly positive from both the developers and the testers. Some students even commented that now, when they play a game, they are always thinking about how the different parts of the game must have been designed and programmed. This, we believe is a success on our behalf as it got our students thinking technically about software that is in everyday use.

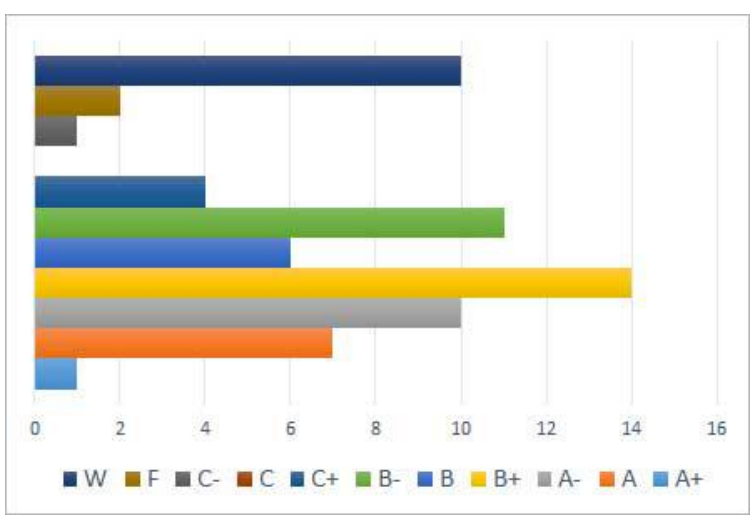

Figure 3. Distribution of grades across all sections

We believe that our efforts for the OOP course did produce positive results. The majority of the students scored above $77 \%$ marks. The course started with a total of 74 students and 15 students withdrew from the course, only the serious students continued with the course. We can see from Figure 3 that the majority of the students managed to score good grades. We also checked if this trend was similar across every section.

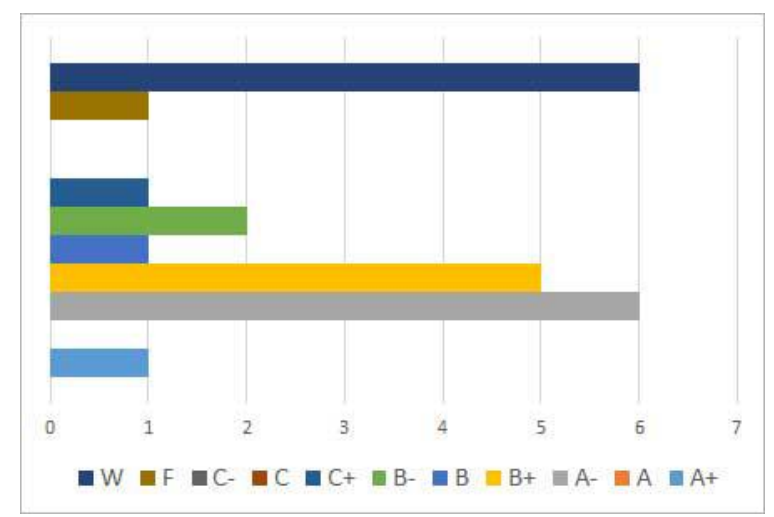

Figure 4. Distribution of grades in Section A

Normally a section contains 24 students and in Figure 4 we can see that more than $50 \%$ of the students in Section A scored B+ or higher grade. This shows that even if the course is tough, if the students are given proper support and motivation, they can produce great results. 


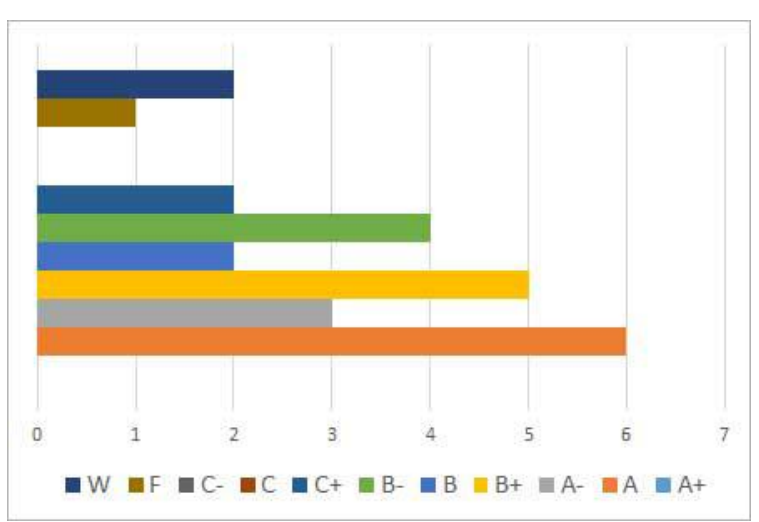

Figure 5. Distribution of grades in Section B

We can see a similar trend in section B where the most grade that was acquired was A.

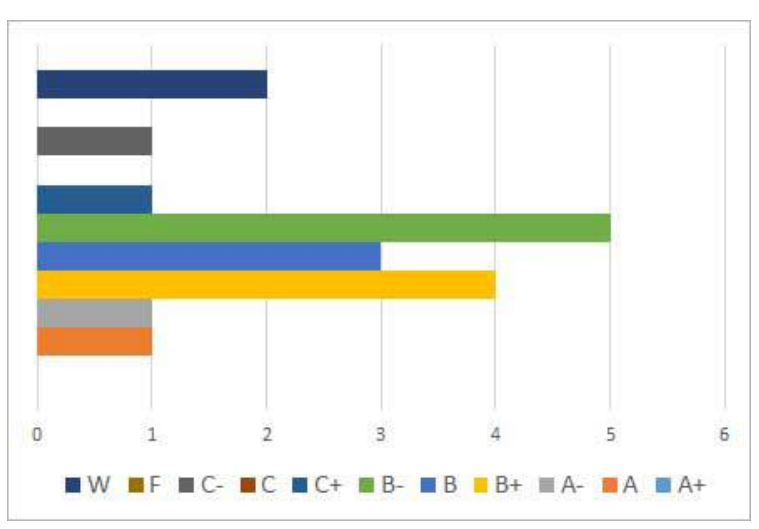

Figure 6. Distribution of grades in Section C

Section C did not fare as well as the other sections but even here we can see that even though the students did not get very good grades but only 2 students scored below B- grade. The same approach is also being followed in fall 2017 semester. This time, the students have taken extra workshops on their own and are better prepared for the course. Most of all, they are excited are learning keenly within the classrooms.

4.1.6. Combining art with technology. For our introduction to programming course, we use Python as the base computer programming language. Python, while easy to understand and use gives a command line interface to its users. Only after importing a few extra libraries does it allow the formation of interesting projects. These libraries however require a good understanding of programming concepts before they can be used by the students. As a result we resorted to using Ren'py[3] for creating the preliminary projects in the middle of the semester. Ren'py requires a very basic understanding of variables and conditionals to make interesting visual novels which can then be ported to different desktop and mobile devices. In order to create these Visual Novels, the students need to be creative on the art side to produce great looking stories. This attracts students from Arts and Humanities department to take part in creating something unique while using technology for their benefit.

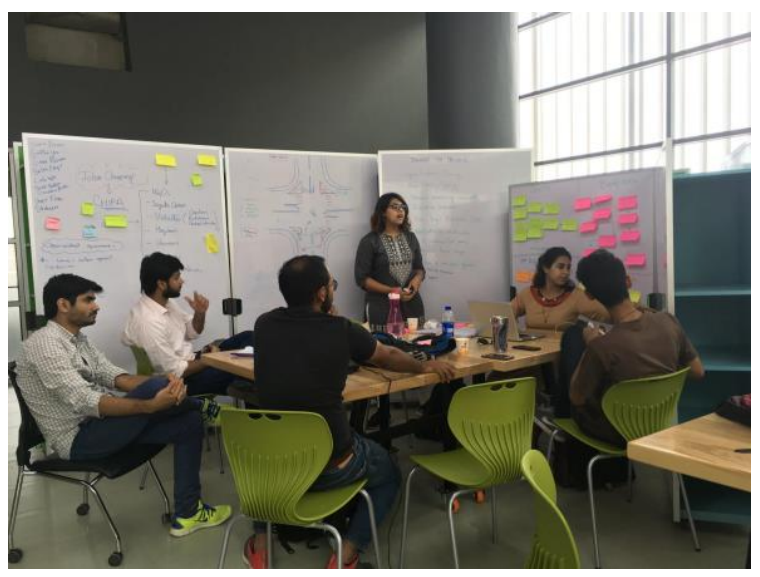

Figure 7. Students participating in a Playground activity

We have also recently inaugurated Habib's Centre for Transdisciplinary, Design \& Innovation, known as 'Playground'. The space has been designed through a collaborative, iterative process itself. It provides the essential elements necessary to create an ecosystem that facilitates faculty and student learning across disciplines. The space currently offers three dynamic zones for hosting workshops, pop-ups and studio sessions with flexible seating and working options. To facilitate ideation and prototyping, we have a dedicated making zone equipped with soft prototyping tools.

The Playground is open for collaborative group work for example, courses with project-based learning, studio-based workshops as well as students' final year projects that require collaborative work. Students who are working on individual theses and projects that require design tools, can also be directed to the Playground. Faculty can also use this space to prototype new courses and ideas as workshops or modules, the Playground team facilitates the process in achieving these goals. Playground also encourages interdisciplinary collaboration to encourage more cohesion among the different departments for the designing of the courses.

In future, we plan to offer a Game Design course which will be done in collaboration with the Arts and Humanities and Social Sciences faculty to come up with game prototypes. The game User Interfaces, Conceptual and Digital Art, Animations and Music will be part of the course and it will incorporate easy to use tools to help with programming and 
deployment. User Interface Design is extremely important for a computer-based system or product.

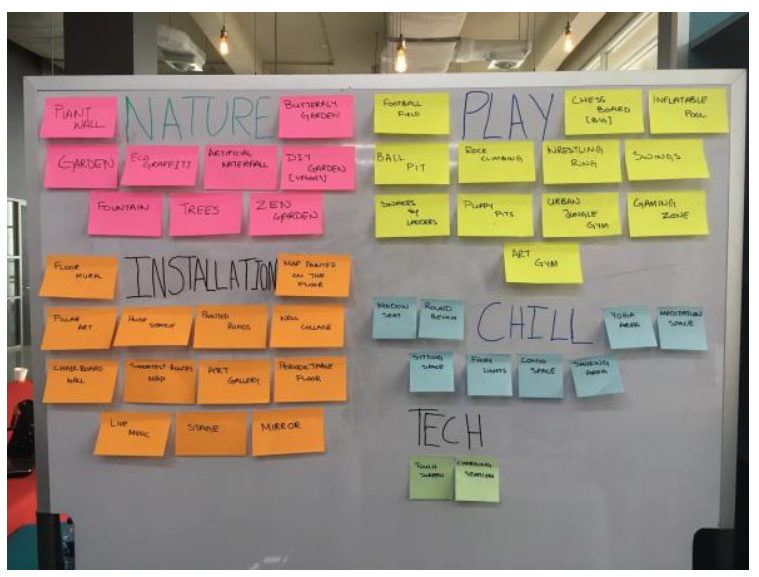

Figure 8. Sample design output of a playground activity

Three important principles guide the design of effective user interfaces:

1. place the user in control,

2. reduce the user's memory load, and

3. make the interface consistent.

To achieve an interface that abides by these principles, an organized design process must be conducted [4]. Habib University offers a program in Communication \& Design as well, which fits in well with the Computer Science program. Playground will provide the space where teachers from these departments can collaborate with each other into coming up with design ideas that might be revolutionary in the long run.

This course will be open to students from every department to maximize the collaboration between students from different schools as well. This in turn might encourage students from the Arts and Humanities department to consider a minor in Computer Science. These students are normally averse to this prospect but we have seen a slight change in their attitudes as we have seen at least one student who changed her major to Computer Science and another who is pursuing a minor in the same. We already have one senior design project which includes one Computer Science and one Communications \& Design student where they are attempting to come up with an idea of an augmented reality application that can help users learn about the history of the city Karachi. The students have one supervisor each from the Computer Science and Communication \& Design departments. The benefits of the Playground design space are already becoming apparent.

\subsection{Learning in Mathematics}

For a population of students that are largely predisposed to rote learning and memorization of formulae, the mathematical competency of students entering University level education generally lacks the necessary critical thinking skills required to tackle higher mathematics. Although the problem of understanding math through appropriate contexts is one that is experienced by students in many countries, yet in Pakistan the problem is further exacerbated by a lack of context and critical thinking in all the other subjects taught at the high school level as well.

4.2.1. Determining competencies. All the incoming freshman students that are enrolled in the School of Science and Engineering are required to take Calculus as the first step in the many Math courses that are a requirement for their Engineering and Computer Science majors. However, given the level of readiness to actively engage and understand the concepts of Calculus (many of which are already introduced to them without much contextual development in high school), students need some remedial help in understanding and analyzing the world of Relations and Functions as a modelling tool. Very few students have looked at function behavior graphically or even numerically and have usually been exposed to formulae that generate some properties (roots, intercepts etc.) of rudimentary functions only symbolically. Most students don't manage to correlate tables and graphs with symbolic expressions and therefore, have very little understanding of local and global behavior of the various kinds of functions. Very few have reflected on the differences between constant and varying rates of change, a fundamental component of the Calculus course.

One of the solutions adopted was the creation of a diagnostic test whereby incoming freshmen could be sorted into students that had the necessary prerequisite understanding to enter Calculus or students that qualified for taking a Pre-Calculus course in the first semester. The diagnostic test assessed basic algebraic and geometric understandings and also determined the extent to which students understood the world of Functions. They were tested on their ability to extend an understanding to a new context, paying equal attention to graphical, numerical and symbolic representations of concepts.

The results of the assessment showed that around $60 \%$ of the incoming freshman for the School of Science and Engineering qualified for Calculus, some barely making it through, and the remaining $40 \%$ were required to take Pre-Calculus in the first semester. For these students to be able to stay in tandem with their cohort for courses that were 
offered during the sophomore year, a summer Calculus II course was offered to ensure that everyone had met the prerequisites for courses offered the next year.

4.2.2. Strategies in the classroom. In the long run, allowing for a course such as Pre-Calculus to solve the problem of necessary prerequisite content was not going to be a stand-alone solution, given that critical thinking skills and fostering creativity were some of the main constituents that we sought to engender in our students across the board. A relational pedagogy [5] in which communication, collaboration and reflection [6] were at the heart of the learning experience had to be adopted. Students were arranged in groups of four or five (the tables were always arranged as such) and were seldom led into the fundamental arguments for a topic via lecture. Instead, they were provided with worksheets that guided them through compelling questions that were meant to be discussed amongst each other before penning proposed answers to them. This allowed for students to have a stake in the material being developed rather than silently accepting content being expounded from a lecture podium or the whiteboard. In this way, we were able to act as facilitators going from one group to another and helping to clarify things that may have remained a unanimous problem for a particular group or to help assist individuals that may have still been struggling with concepts. These strategies were not limited to the Pre-Calculus classroom only but were also employed in the Calculus classroom.

In addition, historical context was often used to allow students to understand the origins of certain concepts, making the subject more accessible and interesting. For example, the unit of Trigonometry was covered in a way where ancient and medieval astronomy was introduced as the basis for making trigonometric tables. Students were then given the opportunity to use their geometric understandings to find sines and cosines of easier angles on their own, thereby investing in a process that was in their direct experience. "The adult mind is so familiar with the notion of logically ordered facts that it does not recognize - it cannot realize - the amount of separating and reformulating which the facts of direct experience have to undergo before they can appear as a "study," or branch of learning. ....The studies as classified are the product, in a word, of the science of the ages, not of the experience of the child." [7]

4.2.3. Assigned Readings. It is often the case that students are expected to read portions of a textbook prior to a class being held on the same topic; a way of preparing them to follow the chain of arguments that are to be demonstrated by a lecturer in the classroom. However, one finds that few text books provide sufficient context for the readings to have any real impact on student learning or understanding when the necessary context is in need of development first.

Instead an alternative approach that was tested with all the classes, Pre-Calculus, Calculus, \& Calculus II, was that of assigning a reading from the textbook after the bulk of the content and the context was established in class through the guided worksheets and intermittent discussions related to the problems that arose in the work being done in the classroom. In this way, the content was already alive in the students' imaginations and the readings then served to bring clarity and further consolidation of concepts.

4.2.4. Diverse assessments. To allow for diverse learners to be assessed in ways that catered to various "facets of understanding" [8] there were a variety of assessment tools used for measuring student learning. Homework assignments were graded purely on the degree of attempt for particular questions and more for completeness than for correctness. This took away some of the anxieties associated with incorrect solutions, which usually prevents further learning and understanding. Before more substantial assessments of entire units, there was always a quiz that was usually a quick assessment of where students were with their concepts, allowing for the instructor and the student to know what needs to be addressed before the big test ahead. In these formal assessments, students were also asked to explain their thinking at times, to ensure that purely mechanical solution schemes were not being memorized without the rationale that supports those methods.

Students were also given term projects that were to be done in groups where there was a component of research, pattern recognition and generalizations based on those patterns, and an extension of topics learned in the core syllabus. Topics ranged from historical perspectives, such as expounding on Newton's ingenuity with the Binomial Theorem, to applications of Calculus, such as explaining and justifying the process of determining a Least Squares line for certain non-linear data. Through these projects students got the opportunity to share their understanding of content and take ownership of various components in the process of piecing together a final presentation of the projects in front of their peers.

A similar strategy was adopted for the Calculus II curriculum, which was much more challenging and had considerably more content to cover overall. In this scenario the term projects not only served as an extension to many of the topics covered but also as a way to ensure that all the learning was not simply generated from the instructor steering the coverage of content. Many topics that would have been 
crammed into the classroom framework were then allowed to be explored by project groups in compelling ways that class time would never have achieved. For example, a project regarding the historical motivation behind Green's Theorem and its proof paved the way for deeper understanding of not only the theorem in question but also of other concepts that bear resemblance to this one. In addition, students explaining a concept to each other has an immeasurable impact on the classroom dynamics, transitioning from a teacher-centered environment to a purely student-centered one.

4.2.5. Software. The use of mathematics software, such as Maple [9], was particularly useful in courses such as Calculus II where visualizing functions in two and three variables can pose significant challenges. The software allowed students to be able to plot all kinds of parametric, multivariable functions and polar functions that would otherwise be cumbersome tasks by hand. This made for a richer experience in the classroom as functions were projected directly onto the whiteboard and discussions about their properties could easily be demonstrated. The software also had all the flexibility that would allow students to manipulated mathematical arguments and visualize the changes occurring when parameters are altered.

The Computer Science faculty also taught the Calculus I course at one point as well and it made use of the Python programming language to exhibit approximations and iterative calculations through computers. In order to facilitate graph plotting through observations, an animation of a boat moving at different velocities was displayed to the students. The animation was created using the language $\mathrm{C}++$ and the Simple Direct Media Layer (SDL) [10] and displayed to the students on a projector. This ended up saving time as we did not need to perform any experiment and also helped us in creating variety as we were able to program the motion of the boat by using different mathematical formulae. This made the class both interactive and interesting as the students could relate well between the real world and the method of observation to record data. The students then plotted the observed graph and tried to come up with the mathematical equation of every plotted graph. This method of teaching is a far cry from what these students are normally used to and it resulted in making the Mathematics classes popular.

\section{Observations}

The strategies employed with the freshmen and sophomores helped to significantly improve student engagement and understanding as it managed to fill the gaps in their previous education. We believe that such initiatives increase student focus and help them develop the necessary skills to perform well in the university environment. We also realize that the university is an experimenting ground where not only the students come to experience a vast number of different teaching techniques but the teachers themselves experiment with different tools and ideas to enhance the overall learning of the students. This is an evolving process and will require a few iterations in every course before we come up with a plan that maximizes learning.

Table 1. Course Evaluation

\begin{tabular}{|c|c|c|}
\hline Course Evaluation & $\begin{array}{c}\text { Section } \\
\text { A }\end{array}$ & $\begin{array}{c}\text { Section } \\
\text { B }\end{array}$ \\
\hline $\begin{array}{l}\text { The syllabus clearly stated } \\
\text { course objectives and learning } \\
\text { outcomes }\end{array}$ & 3.82 & 4.14 \\
\hline $\begin{array}{l}\text { Grading criteria was clearly } \\
\text { stated in the syllabus }\end{array}$ & 3.73 & 4.14 \\
\hline $\begin{array}{l}\text { The material presented in the } \\
\text { course was consistent with the } \\
\text { syllabus }\end{array}$ & 3.27 & 3.71 \\
\hline $\begin{array}{l}\text { The material presented in the } \\
\text { course was engaging }\end{array}$ & 3.55 & 4.57 \\
\hline $\begin{array}{l}\text { The material presented in the } \\
\text { course increased my } \\
\text { knowledge }\end{array}$ & 4.18 & 4.43 \\
\hline $\begin{array}{l}\text { The homework was } \\
\text { appropriate to the level of the } \\
\text { course }\end{array}$ & 3.20 & 3.80 \\
\hline $\begin{array}{l}\text { Assignments helped to } \\
\text { increase my knowledge and } \\
\text { confidence in the subject }\end{array}$ & 4.00 & 4.20 \\
\hline $\begin{array}{l}\text { The course provided } \\
\text { knowledge and tools I will use } \\
\text { in the future }\end{array}$ & 4.20 & 4.43 \\
\hline $\begin{array}{l}\text { The course challenged me in } \\
\text { ways that encouraged my } \\
\text { intellectual growth }\end{array}$ & 3.91 & 4.57 \\
\hline $\begin{array}{l}\text { I would recommend this } \\
\text { course to my friends / peers }\end{array}$ & 3.73 & 4.29 \\
\hline
\end{tabular}

Table 1 contains the evaluations regarding the Computational Thinking I course which contains elements from logical thinking, programming and discrete mathematics. It is a course that provides the students with these core experiences. All the evaluations are done on a scale of 1 to 5 where 5 stands for highest satisfaction.

Table 2 exhibits the satisfaction of students with regards to the instructor. We can see that the trend is very close to a level of 4 which is quite good in a class which contained an average of 24 students. We feel that the students were overall satisfied with both the course and the instructor which for us is a very good sign and a reason for motivation towards implementing new pedagogical techniques. 
Table 2. Instructor Evaluation

\begin{tabular}{|c|c|c|}
\hline Instructor Evaluation & $\begin{array}{l}\text { Section } \\
\text { A }\end{array}$ & $\begin{array}{l}\text { Section } \\
\text { B }\end{array}$ \\
\hline $\begin{array}{l}\text { The instructor clearly } \\
\text { communicated the syllabus }\end{array}$ & 3.90 & 4.29 \\
\hline $\begin{array}{l}\text { The instructor was prepared } \\
\text { for class }\end{array}$ & 4.55 & 4.57 \\
\hline $\begin{array}{l}\text { The instructor presented } \\
\text { course material in an } \\
\text { organized manner }\end{array}$ & 4.27 & 4.29 \\
\hline $\begin{array}{l}\text { The instructor stimulated my } \\
\text { interest in the course }\end{array}$ & 3.55 & 3.86 \\
\hline $\begin{array}{l}\text { The instructor showed respect } \\
\text { towards students }\end{array}$ & 3.91 & 4.00 \\
\hline $\begin{array}{l}\text { The instructor encouraged } \\
\text { class participation }\end{array}$ & 3.82 & 3.71 \\
\hline $\begin{array}{l}\text { The instructor was available } \\
\text { during specified office hours }\end{array}$ & 3.91 & 4.00 \\
\hline $\begin{array}{l}\text { The instructor provided } \\
\text { timely feedback on } \\
\text { assessments }\end{array}$ & 3.90 & 4.00 \\
\hline $\begin{array}{l}\text { The instructor provided } \\
\text { reasons for grades assigned to } \\
\text { me }\end{array}$ & 3.80 & 3.83 \\
\hline $\begin{array}{l}\text { I would recommend this } \\
\text { instructor to my friends / } \\
\text { peers }\end{array}$ & 4.09 & 4.14 \\
\hline
\end{tabular}

We have also observed that the traditional methods of teaching in the university have inherent problems as they do not enable the students to become self-directed, which is extremely important for undergraduate and higher studies. We believe that the amount of active and project-based learning should be encouraged wherever possible in order to give the students a hands-on experience and to understand the utility of their education. Engaging the students on a personal level helped immensely as it gave the students an opportunity to apply their knowledge under supervision and reduced their reluctance in communicating with their instructors. Active learning gives them a sense of ownership as students get emotionally invested in their effort and are eager to learn more, something that we do not generally see in the traditional teaching methodologies.

We also observed that collaboration between students and teachers from different departments produces some interesting combinations. Each individual from a different department brings his/her own way of thinking and the discussion leads towards something new and creative. This continuous exposure between the School of Science and Engineering and School of Arts Humanities and Social Sciences helps in providing a unique productive atmosphere which is unique and one of its kind in Pakistan. Liberal Arts education provides a unique perspective to the engineering subjects which also helps in improving pedagogy across all disciplines.

\section{Conclusion}

Habib University has brought a transformative Liberal Arts and Science education experience to Pakistan. In our pursuit to be at the forefront of educational reform in Pakistan, we looked into the problems that might hinder us in achieving this goal especially in the subjects of Computer Science and Mathematics. We focused on the state of understanding and knowledge of the students that were inducted in the university in the past three years and tried to identify and fill the deficiencies that we encountered through pedagogy. We are using new ideas, design spaces, software and techniques to improve the students' understanding of scientific subjects. We are also trying to increase the interest of liberal arts students towards scientific subjects in order to create a better cohesive atmosphere between the people of different departments may they be teachers or students

A combination of flipped classroom, student engagement dialogues, and project-based learning proved useful in improving the learning process and gave timely feedback to the instructors. Students were also provided with evaluation forms in order to get feedback on the various courses and instructors to ascertain whether there was an atmosphere provided to the students that improved learning. The response has been positive, and we believe that this will only improve with time due to constant revisions and improvements.

\section{Acknowledgements}

We would like to acknowledge the support provided by Habib University for the development of this study. We are grateful to both, the department of Computer Science and Department of Integrated Sciences and Mathematics, for encouraging collaborative efforts towards teaching and learning. Finally, we would like to acknowledge our students without whom this study would not have been possible. Their evaluations are feedback are critical in improving our pedagogical methods and skills and we will strive to improve upon them in the coming years.

\section{References}

[1] D. Lynd, The Education System in Pakistan: Assessment of the National Education Census, Published by UNESCO Islamabad, Pakistan, 2007. 
[2] A. B. Malik, N. Amin, Y. Irfan, M. B. Kakli, Z. F. Piracha and M. A. Zia, Pakistan Education Statistics, National Education Management Information System, Academy of Educational Planning and Management, Ministry of Federal Education and Professional Training, Islamabad, Pakistan, March 2015.

[3] Visual Novel Engine, Ren'py. https://renpy.org. (10 September 2017)

[4] S.Sridevi, “User Interface Design". International Journal of Computer Science and Information Technology Research. ISSN 2348-1196, Vol. 2, Issue 2, pp: (415-426).

[5] Charles Bingham and Alexander M. Sidorkin (editors), No Education Without Relation, Peter Lang Publishing Inc., New York, 2004.

[6] James Hiebert et al., Making Sense: Teaching and Learning Mathematics with Understanding, Heinmann, 1997.

[7] John Dewey, The School and Society and The Child and The Curriculum, The University of Chicago Press 1902.

[8] Grant Wiggins and Jay McTighe, Understanding by Design, Expanded $2^{\text {nd }}$ Edition, Pearson Education, Inc., New Jersey 2006.

[9] Maple - Technical Computing Software for Engineers. https://www.maplesoft.com/products/ maple. (Access date: 10 September 2017)

[10] Simple Direct Media Layer. https://www.libsdl. org/. (10 September 2017) 